THE RADON PROBLEM IN ${ }^{14}$ C DATING

\title{
REIDAR NYDAL
}

Radiological Dating Laboratory, The Norwegian Institute of Technology, Trondheim, Norway

ABSTRACT. Due to traces of radium and uranium in most ${ }^{14} \mathrm{C}$ samples, radon appears as a radioactive contamination in the $\mathrm{CO}_{2}$ prepared by combustion. This contamination must be removed by an active purification prodecure or by storing the $\mathrm{CO}_{2}$ prior to measurement. No effective electronic discrimination against radon and its daughter elements can be performed. The necessary storage time until radon has decayed varies widely, especially for marine shells. The latter material, collected from Norway and Svalbard, has been a main object for the present investigation. In a few cases, a measureable amount of radon may be left even after eight weeks. The behavior of radon and its daughter elements in a $\mathrm{CO}_{2}$ proportional counter has been studied.

\section{INTRODUCTION}

From radium $\left({ }^{226} \mathrm{Ra}\right)$ incorporated in various kinds of material used for ${ }^{14} \mathrm{C}$ dating, it was early discovered that radon $(222 \mathrm{Rn})$ appeared as a source of radioactive contamination. This must be removed before measurement, especially if $\mathrm{CO}_{2}$ is directly used as a counting gas. De Vries (1957) made the first serious attempt to remove radon in $\mathrm{CO}_{2}$ in a slow disti1lation process, but a common method is to store the gas samples for several weeks until radon disappears by natural decay. This laboratory became interested in radon in the late 1950 's when a trend of increasing radon content with age in marine carbonates was observed. A radon counting technique was then developed for seeking an independent time scale based on the radium-uranium ratio in marine calcium carbonate (Nyda1, 1977). After the early successful Th/U dating of coral limestone (Sackett, 1958), it was hoped that the Th/U ratio (or Ra/U ratio) also could be applied for dating old marine shells. It turned out, however, that the method often failed for the latter material (Kaufman et a1, 1971). While studying the Ra/U ratio for a number of old shell samples from Norway and Svalbard (Andersen et al, 1981; Salvigsen and Nydal, 1981), our measurements yielded valuable information about their highly variable radium (and radon) content, especially about the necessary storage time and behaviour of radon and its daughter elements in a $\mathrm{CO}_{2}$ pronortio-
nal counter. 


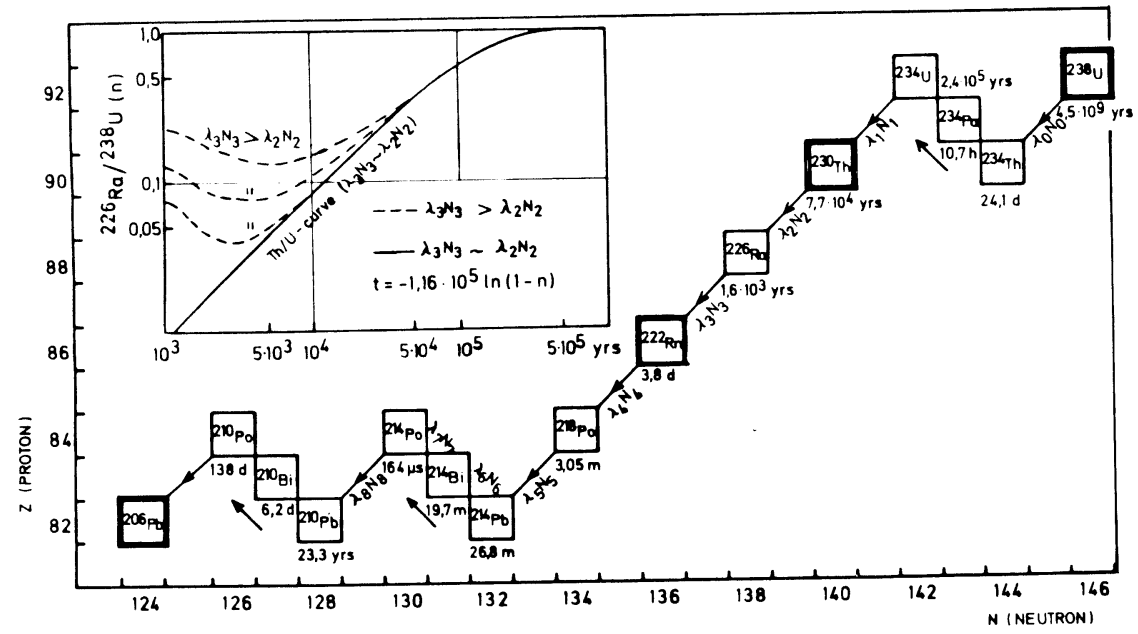

Fig 1. Uranium decay series

\section{RADON AND ITS PROPERTIES}

The important radon isotope is ${ }^{222} \mathrm{Rn}$ with a half-life of 3.8 days. It is the first daughter element of $226_{\mathrm{Ra}}$ and belongs to the $238_{\mathrm{U}}$ series (fig 1 ). Because of the larger halflife of $238 \mathrm{U}\left(3.8 \cdot 10^{9} \mathrm{yr}\right)$ the abundance of $226 \mathrm{Ra}$, and thus, of $222 \mathrm{Rn}$ in nature is relatively high. $222 \mathrm{Rn}$ is a noble gas and thus, the only radioactive element of importance which persists in $\mathrm{CO}_{2}$ after combustion. Radon is normally conserved in unchanged concentration during a purification procedure of $\mathrm{CO}_{2}$ (fig 2).

When $\mathrm{CO}_{2}$ contains radon, four of its daughter elements are built up in the counter, contributing to the counting rate. Two of these are the $\alpha$ emitting elements, $218 \mathrm{Po}$ and $214 \mathrm{Po}$, with respective half-lives of $3.05 \mathrm{~min}$ and $164 \mu \mathrm{sec}$. The other two are the $\beta$ emitters $214 \mathrm{~Pb}$ and ${ }^{214} \mathrm{Bi}$, with half-lives of $26.8 \mathrm{~min}$ and $19.7 \mathrm{~min}$. The $\alpha$ particles from $222 \mathrm{Rn}, 218 \mathrm{Po}$, and $214 \mathrm{Po}$ (respectively, $5.8 \mathrm{MeV}, 6.0 \mathrm{MeV}$, and $7.7 \mathrm{MeV}$ ) result in a separate $\alpha$ plateau where the high-energy $\alpha$ particles can be counted in a separate channel (fig 3). The $\alpha$ pulses can easily be subtracted by means of an anticoincidence unit. The $\beta$ pulses from $214 \mathrm{~Pb}$ and $214 \mathrm{Bi}$, however, cannot be distinguished from the ${ }^{14} \mathrm{C} \beta$ pulses. 


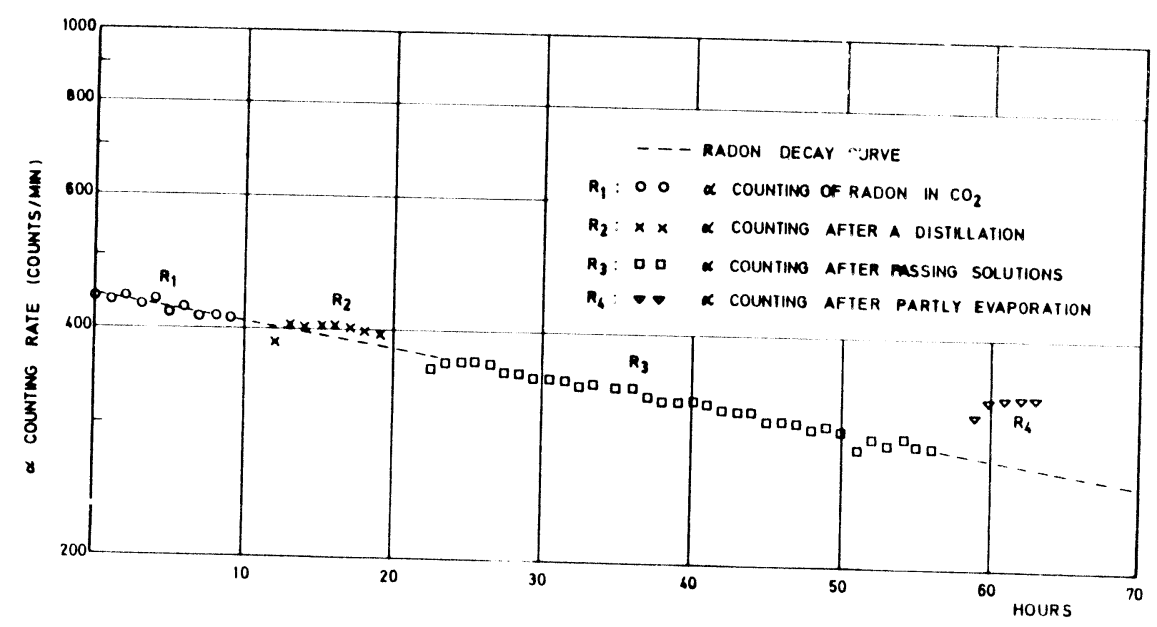

Fig 2. Conservation of radon during various treatments of $\mathrm{CO}_{2}$. Radon is successively observed after an ordinary distillation process $\left(\mathrm{R}_{2}\right.$ : Condensation of $\mathrm{CO}_{2}$ under continuously pumping), $0.3 \mathrm{~L}, 2 \% \mathrm{KMnO}$ ). Radon phase of partly phase of partly evaporated $\mathrm{CO}_{2}$ ice $\left(R_{4}\right)$.

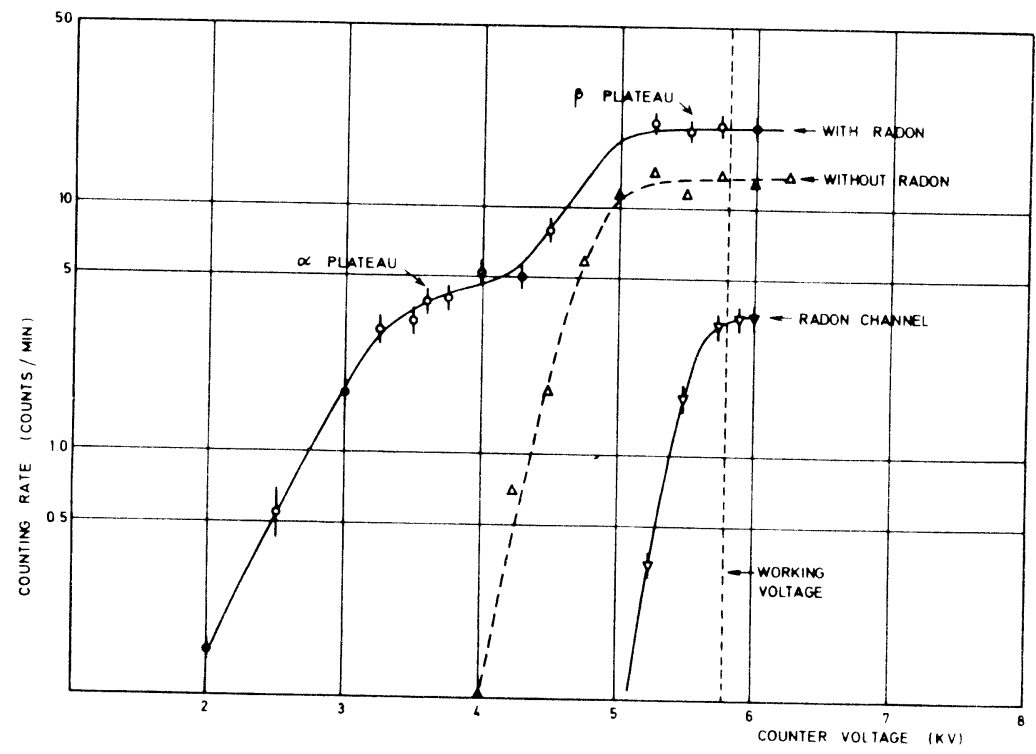
Fig 3. Characteristic curves for $\alpha$ and $\beta$ counting in a $\mathrm{CO}_{2}$
proportional counter. 


\section{DAUGHTER ELEMENTS ON THE COUNTER WALL}

When radon is introduced in a gas proportional counter, the counting rate changes with time. The behavior of radon and the two $\alpha$ emitting daughter elements, $218_{\mathrm{Po}}$ and $214 \mathrm{Po}$, was studied during two experiments in a special counter (Nydal, 1965). In the first experiment, $\mathrm{CO}_{2}$ mixed with radon was introduced into the counter within $10 \mathrm{sec}$, and the $\alpha$ counting rate increased with time because of the build-up of 218 Po and $214 \mathrm{Po}$ (fig 4). The first rapid increase is due to 218 Po with a half-life of $3.05 \mathrm{~min}$. Further and slower increase is due to 214 po with a half-1ife of $164 \mathrm{\mu sec}$. The apparent longer half-life of the latter is due to a delay through the intermediate $\beta$ emitting elements, ${ }^{214} \mathrm{~Pb}$ and $214 \mathrm{Bi}$. After 3.3 hours, an equilibrium ( $99.3 \%$ ) between radon and the daughter elements is almost obtained. The curve has then reached its maximum and decreases later in accordance with the half-life of radon. In the second experiment, radon gas in equilibrium with its daughter elements was quickly removed from the counter and replaced by a neutra1 $\mathrm{CO}_{2}$ gas. The measurements now show the decay of $218 \mathrm{Po}$ and $214 \mathrm{Po}$. The full curve $\left(\mathrm{I}_{\mathrm{f}}\right)$ in figure 5 is calculated from the following set of decay equations:

$$
\begin{array}{ll}
{ }^{218} \mathrm{Po}_{0}: & \mathrm{dN}_{5} / \mathrm{dt}=-\lambda_{5} \mathrm{~N}_{5}+\lambda_{4} \mathrm{~N}_{4} \\
{ }^{214} \mathrm{Po}_{\mathrm{O}}: & \mathrm{dN}_{6} / \mathrm{dt}=-\lambda_{6} \mathrm{~N}_{6}+\lambda_{5} \mathrm{~N}_{5} \\
{ }^{214} \mathrm{Bi}: & \mathrm{dN}_{7} / \mathrm{dt}=-\lambda_{7} \mathrm{~N}_{7}+\lambda_{6} \mathrm{~N}_{6} \\
{ }^{214} \mathrm{Po}_{\mathrm{Po}}: & \mathrm{dN}_{8} / \mathrm{dt}=-\lambda_{8} \mathrm{~N}_{8}+\lambda_{7} \mathrm{~N}_{7}
\end{array}
$$

It is derived from the two experiments that the radon daughter elements ${ }^{214} \mathrm{Po}$ and $218 \mathrm{Po}$ only contribute with 25 per cent each to the total $\alpha$ counting rate. This is because the elements, with a positive net charge just after formation, stick to the counter wall and thus, reduce their activity. One half of the $\alpha$ particles penetrate to the active volume of the counter while the other half is absorbed in the counter wall. The same is true for the $\beta$ emitting elements $214 \mathrm{~Pb}$ and $214 \mathrm{Bi}$. In accordance with the observations, the total counting rate (without anticoincidence) on the $\beta$ plateau is approximately three times that of pure radon. 


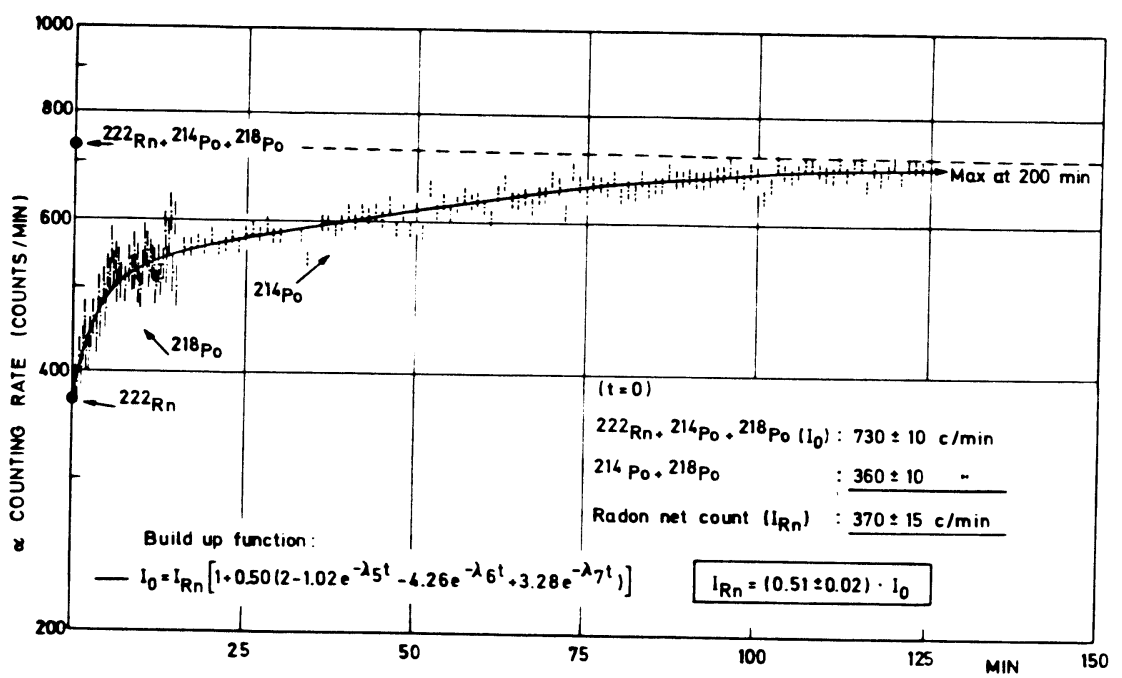

Fig 4. Build up of daughter elements from radon when radon is filled into a gas proportional counter

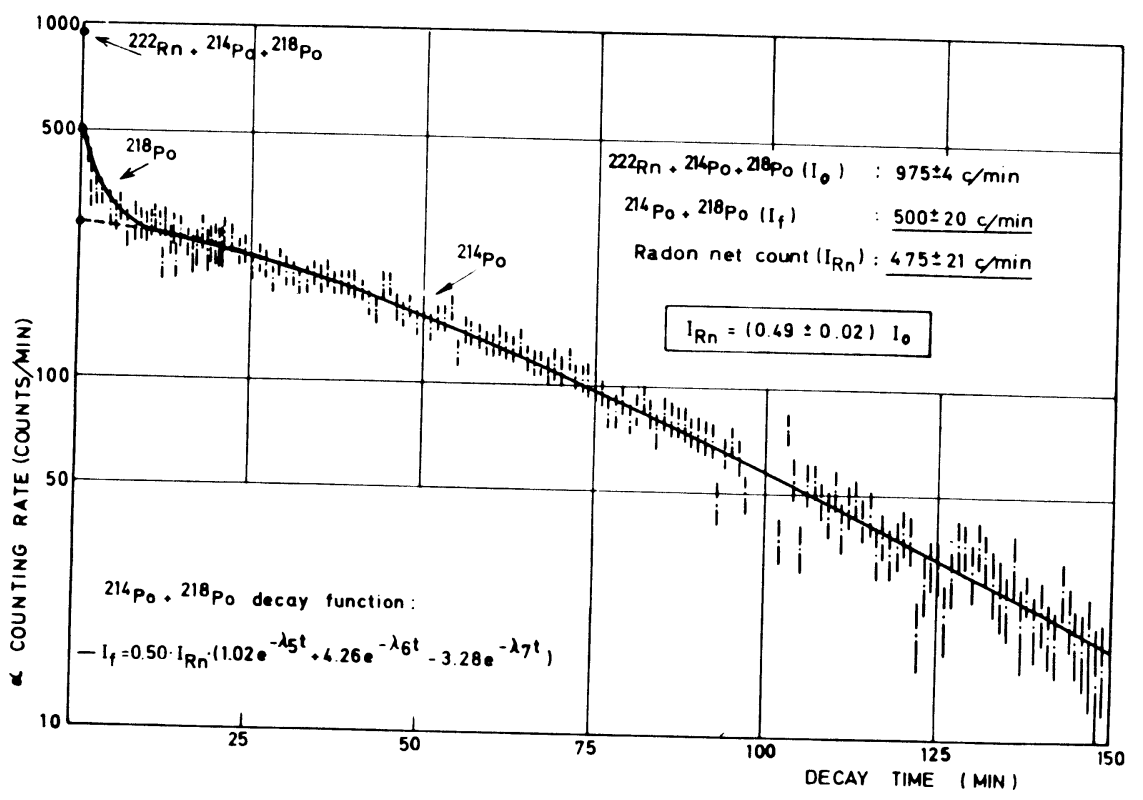

Fig 5. Decay of radon daughter elements on the counter wall when radon is removed from the counter 


\section{RADON FLUSHING SYSTEMS}

The relativly thick center wire $(0.1 \mathrm{~mm})$ of our radon counter and the low pressure ( $<1 \mathrm{~atm})$ greatly reduce the sensitivity for electronegative contamination. Radon can immediately be measured in the $\mathrm{CO}_{2}$ evolved from the carbonate sample in system I (fig 6) without any distillation process. Prior to $\mathrm{CO}_{2}$ preparation, the shells are surface treated and placed in the bulb, and the whole system is evacuated. A predetermined amount of $\mathrm{HNO}_{3}$ is added to the shells, and the reaction allowed to proceed until neutralization. The total amount of $\mathrm{CO}_{2}$ containing radon is transferred into the counter with linuid nitrogen. Radon can also be measured in an alinuot from the solution in the alternative system II (Nyda1, 1977).

propane $\left(\mathrm{C}_{3} \mathrm{H}_{8}\right)$ is presently applied as a flushing gas because it has slightly better counting properties than Co?
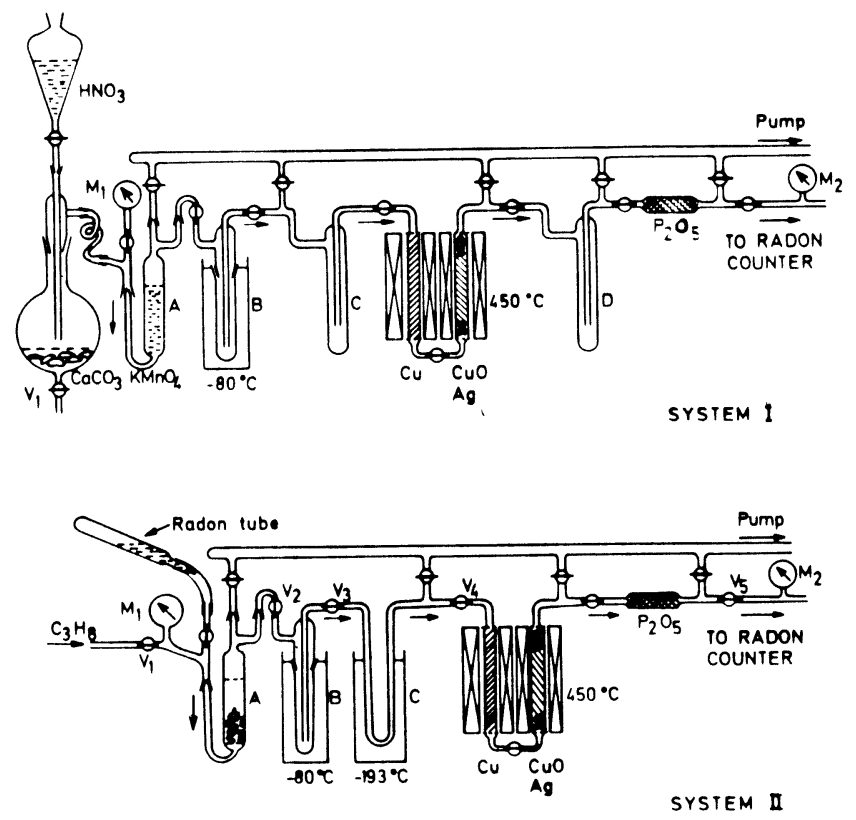

Fig . . Radon flushing systems

\section{RESULTS AND DISCUSSION}

A search for a time scale based on the ${ }^{226} \mathrm{Ra} /{ }^{238} \mathrm{U}$ ratio in marine shells has provided valuable information about the actual radon content in this material. Because of the short 


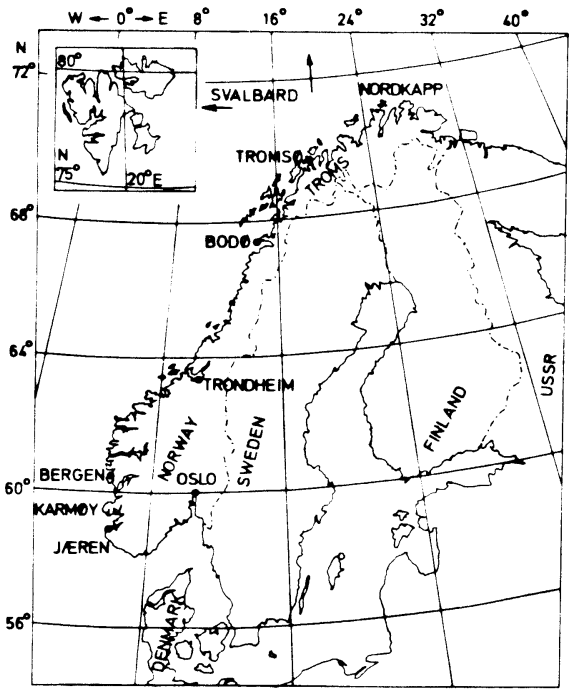

Fig 7. Map of Norway and 1ocations for marine she11s half-life of radon ( 3.8 days) compared to radium (1600 yr), a radioactive equilibrium between these isotopes $\left(\lambda_{3} \mathrm{~N}_{3}=\lambda_{4} \mathrm{~N}_{4}\right)$ exists within the shells. The radium content (counts) min) given in tables $1-3$ is the same as for radon, and is measured with an accurracy of 5-10 per cent ( $1 \sigma)$. Th/U dating is based on the assumption that uranium is out of radioactive equilibrium with its daughter elements in living molluscs at the time of absorntion. Shells must further act as a closed system prior to formation. Under these circumstances, ${ }^{226} \mathrm{Ra}$, which is in enuilibrium with $23 n^{\mathrm{Th}}$

$\left(\lambda_{2} \mathrm{~N}_{2}=\lambda_{3} \mathrm{~N}_{3}\right)$, is built up from ${ }^{238} \mathrm{U}$ according to the time formula given in figure 1 . Because of the long half-1ife of $230 \mathrm{Th}(77,000 \mathrm{yr})$ the amount of radon (counts/min), deriving from incorporated uranium, increases, slowly with time according to

$$
{ }^{222} \mathrm{Rn}=1.15^{238} \mathrm{U}\left(1-\mathrm{e}^{-\mathrm{t} / 1.16 \cdot 10^{5}}\right)
$$

The factor, 1.15, is due to anomalous fractionation effect between the uranium isotopes in nature (Thurber et al, 1965: $\left.{ }^{234} \mathrm{U} /{ }^{238} \mathrm{U} \sim 1.15\right)$. Experience with marine shells shows, however, that the observed radon content does not always follow a simple time formula. In some cases, there is more radium than predicted by uranium decay, and in other cases, there is a deficit. It turns out that shells only exceptionally act as closed systems, and migration of uranium and daughter elements out and into the shells frequently occurs. In single cases, a strong accumulation of uranium is observed. The results presented in tables $1-3$ should give a fairly good cross-section of radon content which may be expected in material from Norway and Svalbard (fig 7). The Th/U ages given in the tables are based on measurements of $226_{\mathrm{Ra}}$ and $238_{\mathrm{U}}$ and calculated in agreement with the above formula. A more accurate Th/U age should, however, be based on direct measurement of the $23{ }^{\circ} \mathrm{Th} /$
${ }^{2} 34 \mathrm{U}$ ratio.

$$
\text { Some former radium and uranium results for } 6000 \text { to } 12,000
$$




\begin{tabular}{|c|c|c|c|c|c|c|c|}
\hline Sample no. & Sample & Loc & $\begin{array}{c}\text { Fraction } \\
:\end{array}$ & $\begin{array}{c}226 \mathrm{Ra} \\
\mathrm{c} / \mathrm{min} 10 \mathrm{~g}\end{array}$ & $\begin{array}{c}238 \mathrm{u} \\
\mathrm{c} / \mathrm{m} \ln 10 \mathrm{~g}\end{array}$ & $226 \mathrm{Re} /{ }^{290 \mathrm{U}}$ & $\begin{array}{c}{ }^{14} \mathrm{C} \text { age } \\
\mathrm{yr}\end{array}$ \\
\hline$T-119 \mathrm{C}$ & Mytilus adulis & Oslo & 90 & 1.1 & 10.9 & 0.10 & $9450 \pm 250$ \\
\hline$T-180$ & Mytilus edulis & Oslo & 90 & 5.2 & 85.0 & 0.06 & $9200 \pm 300$ \\
\hline$T-179$ & Pecten septemr & Oslo & 90 & 9.6 & 4.6 & 2.03 & $9750 \pm 250$ \\
\hline$T-158$ & Pecten septemr & 0810 & 85 & 1.9 & 8.4 & 0.23 & $6950 \pm 200$ \\
\hline$T-1178$ & Macoma calcarea & Fredrikstad & 90 & 1.3 & 1.8 & 0.68 & $9950 \pm 300$ \\
\hline$T-1218$ & Isocandia cor & Fredrikstad & 82 & $13 . n$ & 6.1 & 1.08 & $6570 \pm 150$ \\
\hline$t-123 B$ & Littorina littorsa & Krákerøy & 90 & 0.2 & 0.2 & 1.0 & $6850 \pm 170$ \\
\hline$T-178$ & Macoma calcarøa & Tensberg & 90 & 1.1 & 4.1 & 0.27 & $10,200 \pm 200$ \\
\hline $\begin{array}{l}T-229 A \\
T-229 B\end{array}$ & Mya truncata & Bergen & $\begin{array}{l}41 \\
43\end{array}$ & $\begin{array}{l}2.3 \\
1.5\end{array}$ & $\begin{array}{l}3.2 \\
3.7\end{array}$ & $\begin{array}{l}0.71 \\
0.42\end{array}$ & $10,150 \pm 300$ \\
\hline$T-1428$ & Mya truncata & Bergen & 95 & 0.6 & 0.5 & 0.12 & $11,500 \pm 300$ \\
\hline $\begin{array}{l}T-139 \mathrm{~A} \\
\mathrm{~T}-139 \mathrm{~B}\end{array}$ & Mytilus edulis & Bergen & & $\begin{array}{l}1.0 \\
1.5\end{array}$ & $\begin{array}{l}2.7 \\
7.4\end{array}$ & $\begin{array}{l}0.37 \\
0.20\end{array}$ & $12,700 \pm 350$ \\
\hline$T-112$ & Mya truncata & Trams & 93 & 1.4 & 6.8 & 0.20 & $11,500 \pm 300$ \\
\hline$T-125$ & Mya truncata & Trams & 85 & 1.8 & 7.7 & 0.23 & $9880 \pm 240$ \\
\hline$T-2.14$ & Mya truncata & Trams & 80 & 1.5 & 1.6 & 1.0 & $11,400 \pm 250$ \\
\hline$T-260$ & Mya truncata & Trams & & 1.7 & 4.8 & 0.34 & ca 10,000 \\
\hline
\end{tabular}

year old she1ls (Nydal, 1960; 1962) from various parts of Norway are shown in table 1 . The uranium figures vary widely, from a negligible amount of 0.2 counts/min in $10 \mathrm{~g}$ carbonates $(\mathrm{T}-123 \mathrm{~B})$ at the outer Oslofjord, to a relativly high value of 85.0 counts/min from oslo $(\mathrm{T}-180)$. The uranium content at Oslo is known to be relativly high, which seems to be reflected in the material. The observed radon content in most shell samples is generally very low, partly because of the small contribution from uranium during a relativly short period. A few samples (T-179, -121B, -123B, and -114), however, show a radium and radon content which is much greater than could be predicted from a closed uranium system. Table 2 shows a fairly good agreement between $\mathrm{Th} / \mathrm{U}$ age and ${ }^{14} \mathrm{C}$ age ( for additional details, see Andersen et al, 1981), at least for the innermost fractions, and the measured radium and radon content largely agrees with that derived from incorporated uranium. The shells were well-preserved in hard clay, and the
approach to a closed system seems to be satisfied. $226_{\mathrm{Ra}} /{ }^{23} 8_{\mathrm{U}}$ approach to a closed system seems to be satisfied. ${ }^{226} \mathrm{Ra} /{ }^{23} \mathrm{U}$
ratio has also been measured on a number of samples from Svalbard (Salvigsen and Nydal, 1981), and the most controversial results are shown in table 3 . The series from Phippsøya demonstrate in an instructive way how uranium and radium migrate out and into the shel1, and how the time formula based on the radium-uranium ratio has failed. For the fractions of samples $\mathrm{T}-3101$ and $\mathrm{T}-3100$, radium is either lost during the past, or more reasonably, a major portion of the uranium accumulates at a later stage. The radium and uranium content in sample T3814 constitute, respectivly, 8 and 4 times the earlier ob- 


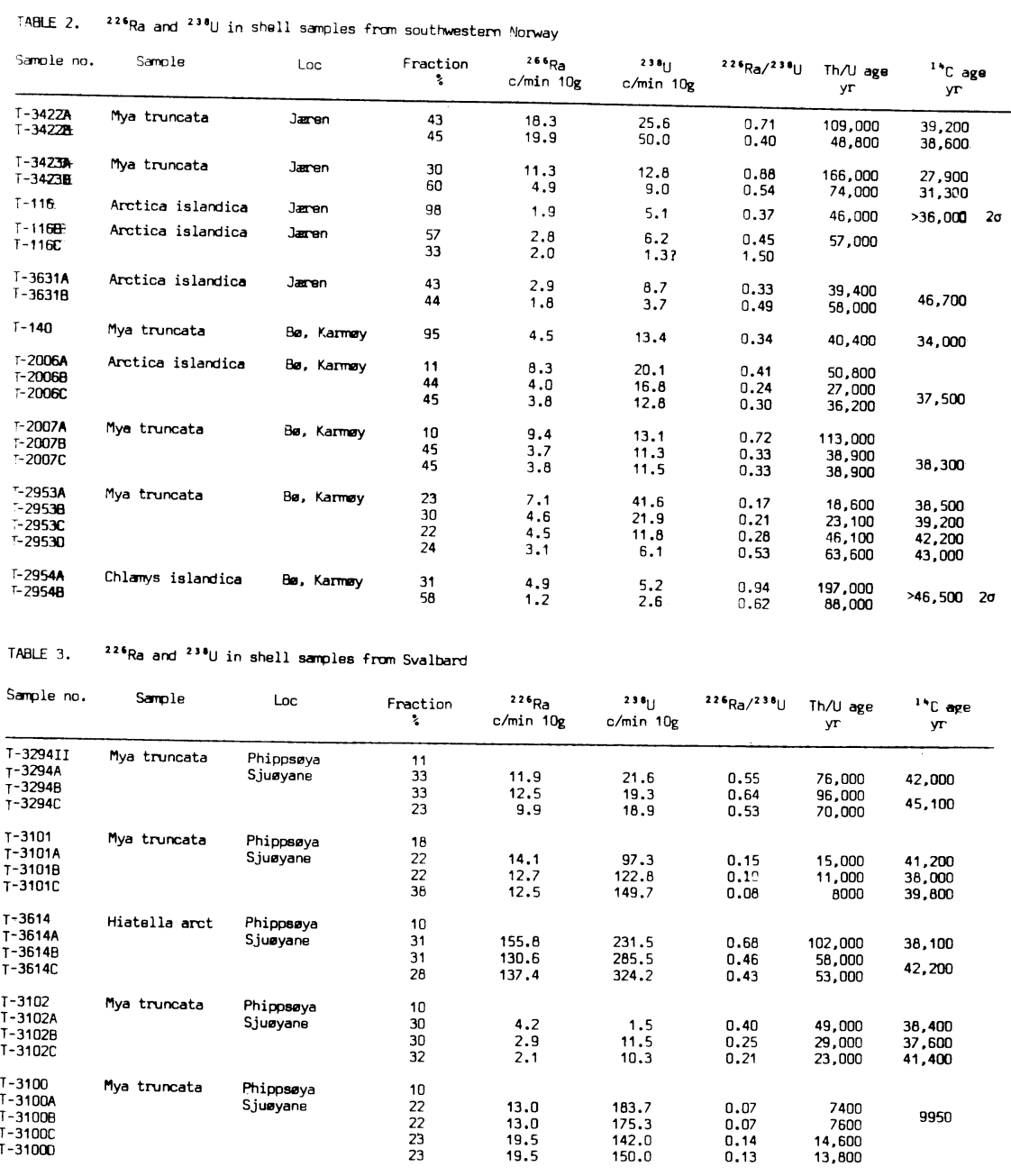

served maximum value. The total radon counting rate for this sample on the $\beta$ plateau (radon + daughter elements) in a $2 \mathrm{~L}$ $\mathrm{CO}_{2}$ proportional counter ( 2 atm pressure) is ca 400 counts $/ \mathrm{min}$ at the time of preparation, decreasing to 0.015 counts/min after a storage time of eight weeks.

However, it is not always practical to wait 6 to 8 weeks until radon is removed by natural decay. The first attempt at physical removal of radon by a slow distillation process (de Vries, 1957) was both critical and time consuming, and has on$1 \mathrm{y}$ been used by a few laboratories. Another method, which now seems to be we11-accepted, is a chromatographic process in which radon is absorbed in charcoal when $\mathrm{CO}_{2}$ passes through. 
Radon can be removed from the charcoal afterwards at a higher temperature. A method that indirectly removes radon is absorbing the $\mathrm{CO}_{2}$ sample in ammonia and further precipitation as calcium carbonate. This procedure was introduced in our laboratory for most samples except shells, for removing electronegative impurities $\left(\mathrm{eg}, \mathrm{SO}_{2}\right)$, but it also serves to remove radon. No chemical or physical process for removal of radon may be absolutely complete, and a storage time of 1 to 2 weeks may still be necessary, especially for very old samples.

\section{ACKNOWLEDGMENTS}

I wish to thank Eiliv Steinnes and Oddvar Johansen, Institute of Atomic Energy, Kjeller, for performing uranium measurements, and Knut Berg, Instrument Center, The Norwegian Institute of Technology, for beautiful drawing of figures.

\section{REFERENCES}

Andersen, B G, Nyda1, R, Wangen, O P, and Mstmo, S, 1981, Weichselian before 15,000 years BP at Jæren-Karmøy in southwestern Norway: Boreas, v 10, p 297-314.

Kaufman, H, Broecker, W S, Ku, T L, and Thurber, D L, 1971, The status of the U-series methods of mollusc dating: Geochim et Cosmochim Acta, v 35, p 1155-1183.

Nydal, R, 1960, Trondheim natural radiocarbon measurements II: Radiocarbon, v 2, p 82-96.

1962, Trondheim natural radiocarbon measurements III: Radiocarbon, v 4, p 160-181.

1965, Ten years trial and error with the $\mathrm{CO}_{2}$ proportional counting technique in Trondheim, in Chatters, $\mathrm{R} M$ and olson, $\mathrm{E} A$, eds, Internat 1 conf on radiocarbon and tritium dating, 6th, Proc: Washington DC, Clearinghouse for Fed Sci Tech Inf, NBS, p 1-16.

1977, Thorium-uranium dating of marine deposited calcium carbonate, in Povinec, P and Usačev, S, eds, Lowradioactivity measurements and applications, Proc: Internat 1 conf, High Tatras, CSSR, p 345-349.

Sackett, W M, (ms) 1958, Ionium-uranium ratios in marine deposited calcium carbonates and related materials: $\mathrm{PhD}$ thesis, Washington Univ, St Louis, Missouri.

Salvigsen, O, and Nydal, R, 1981, The Weichselian glaciation in Svalbard before 15,000 BP: Boreas, v 10, p 434-446.

Thurber, D L, 1962, Anomalous ${ }^{234} \mathrm{U} / 238 \mathrm{U}$ in nature: J Geonhys Res, v 62, p 4518-4520.

Vries, Hessel de, 1957, The removal of radon from $\mathrm{CO}_{2}$ for use in ${ }^{14} \mathrm{C}$ age measurements: Appl Sci Research sec B, $\mathrm{v} 6$, p $461-470$. 